\title{
Árboles del Valle Central de Costa Rica: reproducción del guaitil (Genipa americana L.)
}

\section{Trees of the Central Valley of Costa Rica: reproduction of guaitil (Genipa americana L.)}

\author{
Freddy Rojas-Rodríguez • Gustavo Torres-Córdoba²
}

\begin{abstract}
The following issue presents a brief description about the "Guaitil " (Genipa americana L.) tree , including information about its phenology which directly relates to fruit recollection, seed treatment, nursery, and germination processes.
\end{abstract}

Keywords: Fenología, manejo de semillas, viverización, germinación, árboles.

\section{Resumen}

Se presenta una breve descripción del árbol "Guaitil " (Genipa americana L.), información sobre fenología como base para la recolección de frutos, el manejo de las semillas, la viverización y el proceso de germinación.

Palabras clave: Phenology, seeds treatments, management at nursery, germination.

1. Consultor Independiente; Cartago, Costa Rica; freddyrojasrodriguez@gmail.com

2. Tecnológico de Costa Rica, Escuela de Ingeniería Forestal;

Cartago, Costa Rica; gtorres@tec.ac.cr; (+506) 2550- 2039
Recibido: 23/09/2019

Aceptado: 29/10/2019

Publicado: 19/12/2019

DOI: $10.18845 /$ rfmk.v17i40.4909 


\section{Taxonomía}

Nombre científico: Genipa americana L.

Nombre común: Guaitil, tapaculo, guaitil blanco, caruto o jagua.

Familia: Rubiaceae.

Origen: Nativa.

Distribución en el mundo: Árbol de las selvas bajas de ambas vertientes, desde México hasta Argentina.

Distribución en Costa Rica: : Se encuentra en ambas vertientes, en lugares con climas secos y muy húmedos. [1].

\section{Descripción}

El árbol de guaitil es mediano, caducifolio, de copa irregular con ramas en tendencia horizontal, ancha, alargadas, abierta, normalmente estratificada.

Su fuste por lo general es recto, cilíndrico, sin ramificaciones múltiples, ligeramente acanalado en la base.

La corteza es usada como astringente [1]. Es lisa, gris, oxidándose a un color azulado al hacer un corte; internamente cremosa, suave y arenosa con savia incolora.

Sus hojas son simples, opuestas, están al final de las

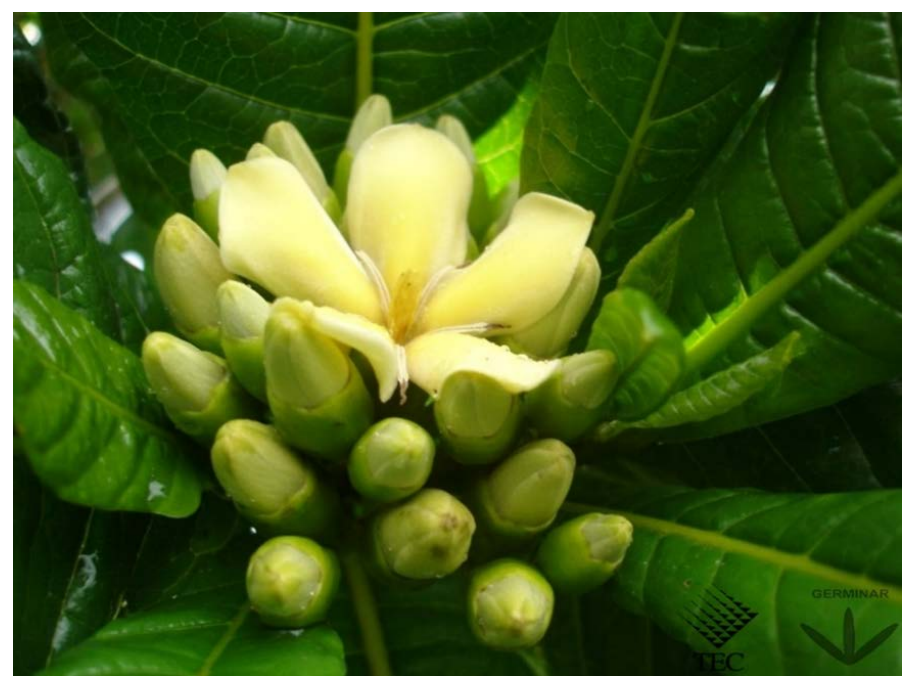

Figura 1. Fruto de Guaitil.

Figure 1. Fruit of "Guaitil" tree. ramillas, ovaladas, elípticas, de 15 a $40 \mathrm{~cm}$ de largo, glabras, a menudo pubescente, lustrosas, cactáceas al secarse y de ramificación simpodial [2].

Las flores son melíferas [1]. Unisexuales, blancas, fragantes, de cinco pétalos, en forma de cima terminal.

Produce frutos carnosos tipo baya color café claro cuando maduro, de forma globosa o subglobosa de aproximadamente $6 \mathrm{~cm}$ de ancho a $8 \mathrm{~cm}$ de largo. De pulpa comestible con un líquido claro que se vuelve azul oscuro al ser expuesto al aire; persistentes en el árbol. [4] Estos en contacto con el aire se torna azules, violáceos y negros con un tinte que antiguamente se usaba para teñir la piel [1].

Sus semillas son de forma ovoide o elíptica, comprimida de 1 a 1,2 cm de largo y de 0,2 a 0,3 cm de grosor. Estas están envueltas en un arilo crema blancuzco. Su cubierta o tegumento es de color crema claro, lisa, lustrosa y coriácea. [2]

Su madera es dura, flexible y de textura fina y se puede trabajar bien en ebanistería a pesar de ser susceptible al ataque de termitas [3]. Se emplea en la construcción civil, mueblería, tornería, batientes de puertas y ventanas, cabos para herramientas e inclusive para carrocerías [2].

\section{Dendrofenocronograma}

En el Cuadro 1 se presenta a continuación información fenológica.

\section{Manejo de semilla y viverización}

Los frutos de guaitil se recolectan en los meses de enero, febrero, marzo y abril. La madurez de sus frutos se reconoce por su color café, textura y dispersión barócora (por peso). La recolección preferiblemente

Cuadro 1. Dendrofenocronograma del Guaitil, en el Valle Central, Costa Rica.

Table 1. Tree phenology through time in "Guaitil", Central Valley, Costa Rica.

\begin{tabular}{|c|c|c|c|c|c|c|c|c|c|c|c|c|}
\hline \multirow{2}{*}{ Características } & \multicolumn{12}{|c|}{ Meses del año } \\
\hline & $\mathrm{E}$ & $\mathrm{F}$ & M & A & M & $\mathrm{J}$ & J & A & $\mathrm{s}$ & 0 & $\mathrm{~N}$ & D \\
\hline \multicolumn{13}{|l|}{ Hojas } \\
\hline Flores & & & & & & & & & & & & \\
\hline Frutos verdes & & & & & & & & & & & & \\
\hline Frutos maduros & & & & & & & & & & & & \\
\hline
\end{tabular}




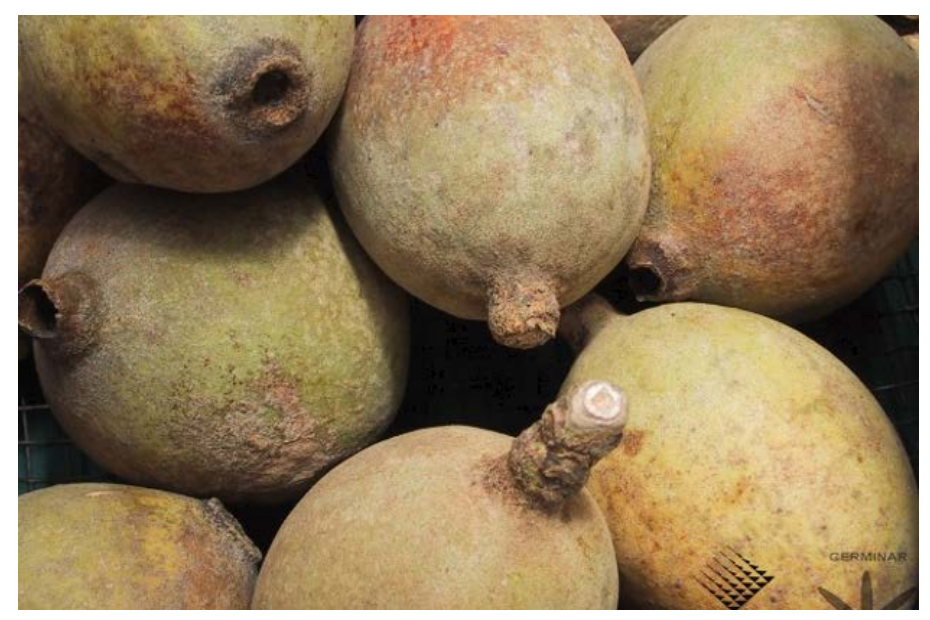

Figura 2. Flor de Guaitil.

Figure 2. Flower of "Guaitil" tree.

debe hacerse directamente del suelo. Los frutos ya maduros se procesan licuándolos para lograr una rápida separación y luego se ponen a secar, para finalmente separar las semillas [4].Proceso de germinación

El tipo de germinación del guácimo ternero es epígea, según la figura 3.

A las semillas se les puede aplicar un tratamiento pregerminativo como un corte en la testa, lo que aumenta el porcentaje de germinación y acorta el período de germinación. Estas se siembran por el método de puntos, en un sustrato a base de arena de río. Se deben cubrir subsuperficialmente, siendo que la germinación se experimenta entre 35-70 días después de la siembra. Su porcentaje de germinación, dependiendo de la calidad del lote de semillas, varía de un $60-84 \%$ y se puede llegar a obtener un total de 12372 semillas por kilo [4].

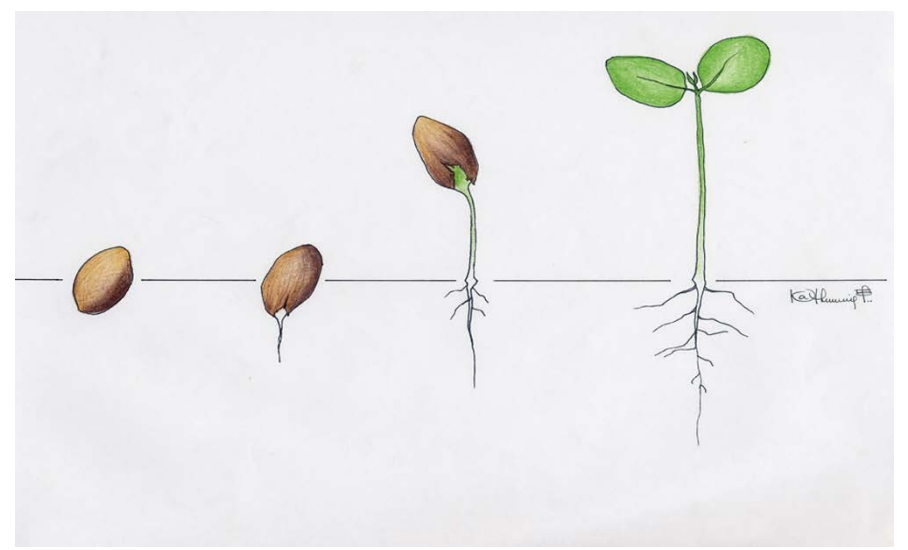

Figure 3. Proceso de germinación del Guaitil.

Figure 3. Seed germination of "Guaitil" tree.
Las plántulas se encuentran listas para su repique o trasplante, bajo el sistema de producción en bolsa plástica, al cabo de dos semanas posteriores a la germinación. En cuanto al mantenimiento, es recomendable aplicar sombra por un periodo no mayor a los 8 días, y es indispensable la aplicación de fertilización química u orgánica para lograr plántulas más vigorosas [4].

\section{Proceso de germinación}

El tipo de germinación del guaitil es epígea, según la figura 3

\section{Referencias}

[1] J. Cordero y D. Boshier Editores. Arboles de Centroamérica: Un manual para extensionistas. Oxford Forestry Institute, Centro Agronómico Tropical y Enseñanza (CATIE), Turrialba. Costa Rica. 2003.

[2] G. Torres, D. Carvajal, F. Rojas y M. Arguedas, "Reproducción de especies arbóreas y arbustivas de la región central de Costa Rica (Germinar 2)", 2011. Disponible: http://www.tec. ac.cr/sitios/Docencia/forestal/Germinar/germinar\%202. html

[3]. J. Salas. Arboles de Nicaragua.Instituto Nicaraguense de Recursos Naturales y del Ambiente. IRENA. Managua. Nicaragua. 1993.

[4] H. Lorenzi. Árvores brasileiras. Manual de identificaçao e cultivo de planatas arbóreas nativas do Brasil. Nova Odessa. Editora Plantarum. Sao Paulo. Brasil. 1992. 